\title{
PROJETO DE EXTENSÃO UNIVERSITÁRIA: UM ESPAÇO PARA FORMAÇÃO PROFISSIONAL E PROMOÇÃO DA SAÚDE
}

\author{
UNIVERSITY EXTENSION PROJECT: A VENUE FOR PROFESSIONAL QUALIFICATION \\ AND HEALTH PROMOTION
}

\author{
José Roberto da Silva Brêtas 1 \\ Sônia Regina Pereira 2
}

Resumo Abordam-se aqui aspectos teóricos e práticos que envolvem um projeto de extensão da Universidade Federal de São Paulo (Unifesp) intitulado Corporalidade e Promoção da Saúde, cuja principal finalidade é articular ações nos campos do ensino, assistência e pesquisa. Este projeto tem por objetivos: proporcionar aos alunos dos cursos de graduação e pós-graduação aprendizagem e vivências no campo da educação em saúde com adolescentes; promover a elaboração e confecção de tecnologias de ensino destinadas à orientação de adolescentes na temática; desenvolver atividades educativas junto a adolescentes e jovens que freqüentam equipamentos sociais e escolas da rede pública; desenvolver pesquisas junto aos serviços que revertam em novas práticas de ensino, intervenção e geração de conhecimento. Seu desenvolvimento ocorre no campo da promoção da saúde, por meio de ações com ênfase nas questões do corpo e sexualidade, direcionadas a adolescentes e jovens que freqüentam escolas de ensino fundamental e médio do município de Embu, São Paulo.

Palavras-chave educação em saúde; formação de recursos humanos; promoção da saúde, relações comunidade-instituição; saúde coletiva.
Abstract This article covers the theoretical and practical aspects involved in a Federal University of São Paulo (Unifesp) extension project called Corporality and Health Promotion, the main purpose of which is to articulate actions in the fields of teaching, assistance, and research. This project is aimed at providing undergraduate and graduate students learning and experience opportunities in the field of health education with adolescents; providing the elaboration of teaching technologies that will be used to guide adolescents in the theme; undertake educational activities among students, teenagers and young people who attend social projects and public schools; develop research projects among the services that will revert to new teaching, intervention, and knowledge generation practices. The project is carried out in the health promotion field, by means of actions that emphasize issues related to the body and to sexuality and aimed at teenagers and young people who attend elementary and high schools in Embu, State of São Paulo.

Keywords health education; human resource qualification; health promotion; community-institution relations; collective health. 


\section{Introdução}

O corpo é nossa presença e morada no mundo, possui concretude física e ocupa um lugar no espaço, dá concretude à existência humana. Pode ser considerado um instrumento de formação e de modificação do mundo, possuindo um poder de ação planejada e uma intencionalidade expressa em seus atos. Essa intencionalidade reflete os desejos, anseios e, sobretudo, suas necessidades humanas. Conhecer e transformar o nosso corpo é conhecer e transformar o mundo. A presença corporal confirma o ser, o estar e o fazer do ser humano no mundo (Brêtas, Lima e Yamaguti, 2006).

Neste contexto, pode-se dizer que adolescência é um período de transição entre infância e idade adulta caracterizado por intenso crescimento e desenvolvimento, que se manifesta por marcantes transformações anatômicas, fisiológicas, psicológicas e sociais. No aspecto psicológico, é a etapa na qual o indivíduo busca a identidade adulta, apoiando-se nas primeiras relações afetivas vivenciadas junto a familiares, já interiorizadas e, verificando a realidade que sua sociedade lhe oferece (Aberastury e Knobel, 1981).

Essas modificações biológicas que caracterizam este processo propiciam a experiência de uma série de eventos psicológicos que culminam na aquisição da identidade sexual, ou seja, das características mentais do sexo correspondente.

As mudanças corporais e sexualidade, nesta fase, são, sobretudo, elementos estruturadores da identidade. Essa função estruturante é, em grande parte, realizada por meio da representação mental que o adolescente tem do seu corpo, ou seja, do esquema corporal (Brêtas, 2004).

Pode-se dizer que adolescência é um momento de (re)descoberta, considerando que a sexualidade se constrói ao longo da vida, a partir da infância, das histórias pessoais dos indivíduos, entremeadas pelas relações interpessoais estabelecidas entre indivíduo e o ambiente no qual vive, em contato com ideologias e visões diferenciadas do mundo. Neste sentido, Foucault (1987) refere que a sexualidade se constrói não apenas no plano biológico, mas principalmente no imaginário: a sexualidade se coloca não apenas no palpável, mas também no discurso que sustenta o palpável, na ideologia subjacente aos padrões de normalidades impostas pela convivência social.

Seguindo esta linha de raciocínio, entendemos que a cidadania também se dá pelo conhecimento e domínio do próprio corpo, pois este é o referencial da existência humana, no espaço, no tempo e meio social. É referência da auto-estima, da liberdade, do prazer sexual, bem como do respeito ao próprio corpo e pelo corpo do outro com quem ele se relaciona.

A sociedade disciplinar em que vivemos está repleta de dispositivos de controle social, sexual e outros, em que técnicas de controle sobre os seres humanos são criadas constantemente, principalmente no que se refere ao 
controle do corpo. Isso ocorre por meio de técnicas de adestramento sociais, educacionais, políticas e tecnológicas, às quais desde muito cedo somos submetidos. Elas fabricam falsos desejos e prazeres representados por ícones que moldam o comportamento, tornando adormecidos os verdadeiros desejos e prazeres que o corpo pode oferecer ao ser humano, o que leva a um processo de alienação sexual.

Os métodos que permitem o controle minucioso das operações do corpo, que realizam a sujeição constante de suas forças e lhes impõe uma relação de docilidade-utilidade, são chamados de disciplinas (Foucault, 1987).

O poder disciplinar é, com efeito, um poder que, em vez de retirar e se apropriar de um 'produto humano', tem como função maior adestrar ou, sem dúvida, adestrar para retirar e se apropriar ainda mais e melhor desse produto (Foucault, 1979).

Para Foucault (1988) o poder seria, essencialmente, aquilo que dita a lei, no que diz respeito ao sexo. O que significa, em primeiro lugar, que o sexo fica reduzido, por ele, a um regime binário: lícito e ilícito, permitido e proibido. O poder prescreve ao sexo uma ordem que funciona, ao mesmo tempo, como forma de inteligibilidade; o sexo se decifra a partir de sua relação com a lei. O poder age pronunciando a regra: o domínio do poder sobre o sexo seria efetuado por meio da linguagem, ou melhor, por um ato de discurso que criaria, pelo próprio fato de se enunciar, um estado de direito.

Sexualidade é o nome que se dá a um dispositivo histórico: não à realidade subterrânea que se apreende com dificuldade, mas à grande rede da superfície em que a estimulação dos corpos, a intensificação dos prazeres, a incitação ao discurso, à formação dos conhecimentos, o reforço dos controles e das resistências, encadeiam-se uns aos outros, segundo algumas grandes estratégias de saber e de poder (Foucault, 1988).

Neste contexto, a escola, pela sua importância no campo de socialização do escolar e adolescente, seria um importante veículo para a educação sexual. Mas, devido a variáveis como o despreparo dos professores para discussão do tema e a reprodução de uma ideologia de dominação que utiliza mecanismos de controle como a repressão ou a biologização da sexualidade, com a conivência das ciências médicas, acaba por vincular o exercício da sexualidade somente como uma prática das funções reprodutoras. Esta equivalência imposta entre sexualidade e reprodução, como um fenômeno essencialmente biológico, objetivo, palpável por meio dos filhos gerados, ocasiona uma cisão entre a sexualidade e a subjetividade, restando apenas informações sobre reprodução, anatomia, fisiologia, Aids e contracepção, deixando de lado a subjetividade, seja da criança ou do adolescente.

A realidade nos mostra que ignorar o tema ou privilegiar o aspecto informativo não é suficiente, pois as informações sobre conduta contraceptiva e prevenção à Aids não asseguram sua eficácia entre os adolescentes. 
Isso talvez ocorra porque a subjetividade tem mais influência que as informações dadas aos adolescentes (Brêtas e Silva, 2005).

A maneira predominante desse modelo de educação sexual é aquela em que o educador tenta eliminar a própria sexualidade, e espera-se que sufoque também a sexualidade dos estudantes. Desde que ele fale sobre anatomia e fisiologia estará tudo bem, e melhor ainda se expuser normas que confundem a sexualidade. Neste modelo, dificilmente se tolera que o professor tenha um discurso sobre a essência do problema, que é o binômio prazeramor (Bernardi, 1985).

O termo responsabilidade é muito utilizado como um instrumento repressivo, principalmente quando se trata do exercício da sexualidade. $O$ discurso utilizado é sutil, impõe a culpa, impedindo assim que os jovens possam assumir a verdadeira responsabilidade de estarem juntos em uma interrelação segura do ponto de vista da saúde sexual, com troca recíproca de amor e prazer.

Outro aspecto importante diz respeito às dificuldades que os pais apresentam em abordar questões de sexualidade com seus filhos, justamente por não terem muito claro o que aconteceu com eles próprios. Desta maneira, a maioria dos pais atribui a tarefa da orientação sexual de seus filhos à escola e esta, por sua vez, apresenta dificuldade em cumprir tal tarefa. É importante considerar também o fato de que o professor pode sentir-se despreparado em lidar com aspectos da orientação sexual junto a seus alunos.

Temos de pensar em sexualidade, família e escola pelo princípio da não exclusão, isto é, pensarmos em sistemas interagentes que estabeleçam processos cujos princípios de convergência (vinculação, união) e complementaridade (respeito pelas diferenças) estejam estabelecidos (Meirelles, 1997).

A sexualidade articula processos biológicos e socioculturais. Embora tenha uma expressão singular em cada sujeito, é um processo subjetivo, mediado pelo corpo, da experiência, da troca, da procura, das projeções construídas em meio à vida. Ela é um componente humano que se define a partir da complexa inter-relação entre biologia, subjetividade e condições existenciais concretas. A complexa inter-relação entre corpo biológico, subjetividade e influências socioculturais é que dá especificidade ao exercício da sexualidade dos diferentes grupos. As várias manifestações refletem sempre, de modo único e singular, a individualidade de cada sujeito e, de modo coletivo e plural, a marca dos espaços específicos onde é exercida (Mandú e Corrêa, 2000).

Devido à influência da cultura patriarcal, a religião, escola e ciência mecanicista ainda mantêm o pensamento dualista acerca do ser humano, no sentido corpo-máquina e alma, em que tentam fazer crer que o ato sexual existe unicamente para procriar. Reich (1988) se contrapôs a esta forma de 
pensar, entendendo que o relacionamento sexual é praticado porque existe o impulso da tensão sexual, que na adolescência é notadamente aumentado pela ação hormonal e busca uma via de descarga. Na realidade, devemos considerar o grande problema da excitação sexual e do prazer proibido descoberto durante a gratificação sexual.

A adolescência é um momento em que a experimentação da sexualidade colabora na estruturação de identidades. Assim, preconceitos, tabus, interdições e valores organizam as possibilidades sexual-afetivas dos indivíduos nesta faixa etária. Também é ciclo decisivo para demarcação de diferenças de gênero. Tais diferenças podem tanto potencializar, por exemplo, a criatividade e a singularidade como também reproduzir divisões sexualizadas com conotação de assimetria e desigualdade. No discurso dos adolescentes, a sexualidade se entrelaça tanto com afetividade, quanto com sociabilidade e relações sociais de diferentes ordens. Tanto provoca a galhofa, com ênfase nos discursos sobre prazer e amorosidade, quanto medos, preocupações e cuidados, ainda que tal tônica esteja mais presente nos discursos de pais e professores, tendo em vista que se relaciona aos tempos de Aids e aumento da gravidez juvenil (Rodriguez et al., 2004).

Com toda a mudança de comportamento que o contexto histórico nos impõe, a atividade sexual é cada vez mais precoce, contrariando a tese do senso comum de que a orientação sexual estimula precocemente o início das relações sexuais. O grande e atual problema é a gravidez na adolescência, que está associado a altas taxas de morbimortalidade materna, maiores riscos de aborto, complicações no parto e prematuridade. Do ponto de vista social, há que se considerar o aumento no potencial de perda de oportunidades educacionais e de trabalho, entre as adolescentes que engravidam, pois podem ser forçadas a abandonar a escola mais cedo e, portanto, ter reduzidas as chances de conseguir inserir-se em atividades produtivas que exijam maior qualificação.

Tendo por base a problemática que envolve o adolescente - a mudança corporal, a sexualidade e a relação do adolescente-sociedade -, foi concebido o projeto de extensão universitária denominado Corporalidade e Promoção da Saúde.

Para nortear nossa prática educativa, nos pautamos no pressuposto de que ensinar não é transferir conhecimento, mas criar possibilidades para que os indivíduos implicados em uma ação pedagógica possam participar da produção compartilhada do conhecimento (Freire, 1996).

Para tanto, foi preciso ouvir e observar os sujeitos com quem trabalhamos, utilizando uma abordagem mais participativa para que pudéssemos interagir com as subjetividades emergentes desta relação-educação e principalmente possibilitar ao adolescente a leitura e compreensão da realidade. Assim, foi necessário adotar teorias e metodologias que atendessem a ampli- 
ação dos canais de percepção e comunicação para possibilitar a compreensão das distintas realidades com as quais entramos em contato.

Para o desenvolvimento de nossas ações de ensino-aprendizagem, estabelecemos, como núcleo central, a adolescência e definimos, como matriz metodológica para compreensão dos fenômenos e para o direcionamento do projeto, os pressupostos das representações sociais.

As representações sociais são um conjunto de conceitos, proposições e explicações originadas na vida cotidiana no curso de comunicações interpessoais, envolvendo saberes populares e do senso comum, elaborados e partilhados coletivamente, com a finalidade de construir e interpretar o real (Moscovici, 2003). Elas propiciam uma maneira de entendermos como as noções e os modos de pensamento construídos na trajetória de vida dos sujeitos, influenciados, por conseguinte, pela experiência coletiva, pelos fragmentos das teorias científicas e dos saberes escolares, expressos, em parte, nas práticas sociais, podem ser mobilizados e transformados para servir à vida cotidiana.

A partir deste desenho teórico-pedagógico, iniciamos as atividades do projeto extensão universitária Corporalidade e Promoção da Saúde, promovendo discussões junto aos atores que compõem o universo das escolas (adolescentes, professores, pais), subsidiadas por dados de pesquisas anteriormente desenvolvidas junto a esta população. Foi a maneira encontrada para documentar e compreender os interesses acerca da temática. Posteriormente esse conteúdo norteou a sistematização e operacionalização das nossas ações.

Este projeto está vinculado ao Grupo de Estudos sobre Corporalidade e Promoção da Saúde (Gecopros). Com o passar do tempo, caracterizou-se por um conjunto de atividades que engloba a problemática das questões da adolescência. Seu campo de atuação é a promoção da saúde, com ênfase nas questões do corpo adolescente (desenvolvimento e mudanças corporais, imagem corporal e auto-estima, sexualidade, comportamento sexual, saúde sexual, relações interpessoais, corpo social, ações preventivas; abuso sexual), e visa a catalisar discussões e reflexões críticas sobre esse universo.

A extensão, como prática acadêmica, visa a interligar a universidade em suas atividades de ensino e pesquisa com as demandas da sociedade, buscando respeitar o compromisso social da universidade. A relação entre extensão e pesquisa ocorre, sobretudo, pelo papel que esta passa a desempenhar como (re)criadora de conhecimentos, além de contribuir para a transformação da sociedade.

O projeto tem como principal finalidade articular ações nos campos do ensino, assistência e pesquisa. Na área do ensino procuramos: a) proporcionar, ao aluno do curso de graduação em Enfermagem da Unifesp, aprendizagem e vivências no campo da Educação em Saúde com adolescentes; 
b) promover a elaboração e confecção de tecnologias de ensino destinadas à orientação de adolescentes na temática abordada pelo projeto. Na extensão, busca-se desenvolver atividades educativas junto a adolescentes e jovens que freqüentam equipamentos sociais e escolas da rede pública. E na pesquisa, adotamos o desenvolvimento de estudos junto aos serviços que possam reverter em novas práticas de ensino, intervenção e gerar conhecimento.

\section{Construindo um projeto de extensão}

Nossa práxis direciona-se principalmente à população de adolescentes entre 10 e 20 anos de idade que freqüentam quatro escolas públicas de ensino fundamental e médio da região de Santo Eduardo do município de Embu, São Paulo. Desenvolve-se por meio de atividades como: oficinas de orientação sexual; curso para formação de multiplicadores em orientação sexual; oficinas de autoconhecimento e prevenção do câncer de mama; aplicação do jogo Sexgame.

As atividades do projeto estão vinculadas ao Programa de Integração Docente-Assistencial do Embu (Pida/Embu), instituído em 1970 e caracterizado pela integração de ações desenvolvidas por diferentes departamentos acadêmicos da Universidade Federal de São Paulo, com a população moradora deste município. Embu é um município da Região Metropolitana de São Paulo, com população de 218.535 habitantes, dos quais $40 \%$ têm menos de 20 anos. É uma área bastante afetada pelos altos índices de desemprego, violência e exclusão social.

Para atender as necessidades desveladas, o conceito de ação adotado foi o de 'orientação sexual', que pode ser conceituado como o processo de intervenção sistemática na área da sexualidade humana e que se propõe a fornecer informações sobre sexualidade. Visa também organizar um espaço de reflexões e questionamento sobre a importância da prevenção, mudanças corporais, identidade, postura, relações interpessoais, auto-estima, relações de gênero, tabus, crenças e valores a respeito de relacionamentos, comportamentos sexuais e doenças sexualmente transmissíveis (DST).

A orientação sexual tem basicamente três objetivos: suprir as lacunas de informação do adolescente; refletir sobre os preconceitos, de maneira especial os referentes ao masculino e feminino, assim como sobre os conflitos próprios dessa faixa etária, criando um espaço afetivo onde possa falar ou representar angústias e medos. O termo orientação sexual deriva do conceito pedagógico de orientação educacional, o qual se define como um processo de intervenção sistemática na área da sexualidade, realizado principalmente em escolas (Suplicy, 1994). A operacionalização se dá por oficinas como um trabalho estruturado de grupos, que são desenvolvidas por 
docentes, monitores de extensão, pós-graduandos e alunos da segunda série do curso de enfermagem que fazem estágio de educação em saúde.

As oficinas têm, como princípios fundamentais: ser uma experiência de crescimento pessoal e aprendizagem (tanto para o orientador como para o orientando); constituir-se em um meio social e cultural que molda a forma pela qual os indivíduos aprendem e expressam sua sexualidade; que a sexualidade é fundamental para a vida do ser humano e se manifesta de várias maneiras; que os cuidados com o próprio corpo requerem informações adequadas, atitudes preventivas específicas e acesso a serviços de saúde de boa qualidade.

Procuramos abordar a sexualidade como um aspecto natural e positivo da vida humana, proporcionando a livre discussão de normas e padrões de comportamento em relação ao sexo e o debate das atitudes das pessoas diante da própria sexualidade.

Tais premissas proporcionam, ao adolescente, condições para identificar e refletir sobre os valores socioculturais e posicionar-se de forma pessoal em relação a eles; identificar e expressar seus sentimentos; desenvolver a auto-estima; compreender que a sexualidade faz parte do desenvolvimento humano; relacionar o comportamento sexual a respeito e responsabilidade; reconhecer e respeitar as formas de opção sexual; relacionar as diferentes manifestações da sexualidade à cidadania; discernir entre comportamentos sexuais enriquecedores e prejudiciais a si e aos outros; aprender a conhecer o próprio corpo e a cuidar dele; prevenir-se de abusos sexuais; evitar contrair e transmitir as DST; vencer tabus e preconceitos relacionados à sexualidade; evitar comportamentos discriminatórios e intolerantes; e viver a sexualidade de forma congruente com os próprios valores.

Essas oficinas se caracterizam, principalmente, por serem participativas e envolverem um processo que estimule o compartilhamento de idéias, trocas, questionamentos e a expressão das experiências e dos valores dos adolescentes.

Outra atividade do projeto direciona-se para a formação de multiplicadores, instrumentalizando adolescentes e professores para atuarem em orientação sexual, junto ao ambiente da escola e na comunidade. Para atingir esta finalidade, utiliza-se uma práxis metodológica que envolve atividades no campo teórico-vivencial. A formação está organizada em três módulos: construção biológica da sexualidade; construção social da sexualidade; construção psicológica da sexualidade.

Com relação às oficinas de autoconhecimento e prevenção do câncer de mama, as atividades desenvolvidas estão direcionadas à promoção da saúde, por meio de práticas educativas para o fortalecimento de uma cultura para autoconhecimento corporal e aquisição de atitudes relacionadas aos fatores de risco (auto-exame das mamas na detecção precoce do câncer), e também 
à formação de multiplicadoras. Pois, na adolescência, as modificações biológicas propiciam a experiência de eventos físicos e psicológicos que facilitam o autoconhecimento e aquisição de hábitos de prevenção à saúde.

Ao vivenciarem as atividades propiciadas pelo projeto, monitores de extensão elaboraram um instrumento lúdico e didático denominado sexgame. Este instrumento consiste em um jogo de perguntas e respostas com cinco temas relacionados à adolescência: puberdade; relação sexual; relações interpessoais; DST/Aids e prevenção; gravidez e adolescência. Seu objetivo é transmitir informações, ampliar os conhecimentos dos adolescentes e fazêlos refletir acerca do seu universo de descobertas. Esse instrumento tem sido um método interessante e eficaz de aprendizagem e de fixação dos conhecimentos adquiridos nas atividades educativas.

Desde março de 2004, quando iniciamos as atividades do projeto de extensão universitária Corporalidade e Promoção da Saúde, até outubro de 2006, nas escolas em que o projeto está inserido, participaram 2.914 adolescentes entre 10 e 20 anos (1.481 do sexo feminino e 1.433 masculino). Nesse período, desenvolvemos 220 oficinas com 800 horas de atividade, distribuímos 22.176 preservativos masculinos, proporcionamos estágio curricular a 321 estudantes do curso de graduação em Enfermagem da Unifesp, além do desenvolvimento de sete pesquisas de iniciação científica com bolsas do CNPq e Fapesp.

A repercussão dessas atividades junto à coletividade nos surpreendeu pelo grau de envolvimento e participação. Assim, como desdobramento, os pesquisadores estão iniciando um processo de avaliação das oficinas com a finalidade de dimensionar o impacto do conhecimento transmitido aos sujeitos participantes. Paralelo a isso, em 2008 o Gecopros vai oferecer um curso de especialização em Sexualidade Educacional para professores da rede pública de ensino fundamental e médio que tenham formação universitária.

\section{Considerações finais}

Temos constatado que o tema sexualidade continua sendo um tabu em nosso meio, acentuando-se apenas o que é negativo e prejudicial do sexo. O que é biológico e psicologicamente positivo, e constitui a base do amor, do prazer, da convivência, da família e da própria sobrevivência humana é, muitas vezes, ignorado. Assim, entendemos que os profissionais que atuam na área da saúde e afins encontram-se em uma encruzilhada política e micropolítica fundamental: reproduzir modelos em que não há saídas para os processos de singularização, ou, ao contrário, trabalhar com o indivíduo considerando suas singularidades e incorporando-as como parte desse processo.

O desenvolvimento de nosso trabalho está alicerçado na problemática associada às questões da corporalidade na adolescência enfatizando o corpo 
e suas vicissitudes, promovendo discussões e reflexões críticas sobre esse universo e incentivando a busca de novas soluções e contribuições. Esta ação está sendo construída em estreita parceria com os estudantes do curso de Enfermagem, os adolescentes e professores das escolas envolvidas no projeto, visando uma maneira de pensar e de fazer promoção de saúde.

Mediante esta experiência, estamos aprendendo que o caminho da prática libertária se faz compreendendo o interesse do adolescente pela sexualidade, promovendo a saúde sexual e a cidadania nas inter-relações, que essas ações não significam libertinagem, mas facilitam o contato sadio e protegido entre os adolescentes de ambos os sexos. A sexualidade, quando compreendida e adequadamente canalizada, se traduz em amor, criatividade, potência geradora de progresso e de desenvolvimento.

A prática do ensino-aprendizagem desvela a necessidade de transformar o conhecimento em caso pessoal, de promover a subjetivação do conhecimento acadêmico, ou seja, transformar espectadores, nem sempre muito interessados, em atores que entendam e construam, de forma consciente, a sua história sexual-afetiva.

Também implica um esforço pedagógico pessoal e coletivo, com a racionalidade e a objetividade próprias da pedagogia, associada à abordagem da dimensão afetivo-emocional da pessoa, de modo a permitir a desconstrução de preconceitos e tabus e a reconstrução social dos valores, das crenças sociais e historicamente construídas.

\section{Notas}

1 Professor adjunto da Universidade Federal de São Paulo (Unifesp), São Paulo, Brasil. Doutor em Enfermagem pela Unifesp.<jrbretas@denf.epm.br>

2 Professor adjunto da Universidade Federal de São Paulo (Unifesp), São Paulo, Brasil. Doutora em Enfermagem pela Unifesp. <sore@denf.epm.br> 
ABERASTURY, Arminda; KNOBEL, Maurício. Adolescência normal. Porto Alegre: Artes Médicas, 1981.

BERNARDI, Marcelo. A deseducação sexual. São Paulo: Summus Editorial, 1985.

BRÊTAS, José R. S. A mudança corporal na adolescência: a grande metamorfose. Temas sobre Desenvolvimento, v. 12, n. 72, p. 29-38, 2004.

.; SILVA, Conceição V. Orientação sexual para adolescentes: um relato de experiência. Acta Paulista de Enfermagem, v. 18, n. 3, p. 326-33, 2005.

.; LIMA, Renata C.; YAMAGUTI, Lie. O corpo que cuidamos. In: BRÊTAS, Ana C. P.; GAMBA, Mônica A. (Orgs.). Enfermagem e saúde do adulto. São Paulo: Manole, 2006. p. 11-25.

FOUCAULT, Michel. Microfísica do poder. Rio de Janeiro: Graal, 1979.

. Vigiar e punir: história da violência nas prisões. Petrópolis: Vozes, 1987

.História da sexualidade I: a vontade de saber. Rio de Janeiro: Graal, 1988.

FREIRE, Paulo. Pedagogia da autonomia: saberes necessários à prática educativa. São Paulo: Paz e Terra, 1996.
MANDÚ, Edir N. T.; CORRÊA, Áurea C. P. Educação sexual formal na adolescência: contribuições à construção de projetos educativos. Acta Paulista de Enfermagem, v. 13, n. 1, p.27-37, 2000.

MEIRELLES, João A. B. Os Ets e a gorila: um olhar sobre a sexualidade, a família e a escola. In: AQUINO, Julio G. (Org.). Sexualidade na escola: alternativas teóricas e práticas. São Paulo: Summus Editorial, 1997. p. 71-86.

MOSCOVICI, Serge. Representações sociais: investigações em psicologia social. Petrópolis: Vozes, 2003.

REICH, Wilhelm. Psicologia de massas do fascismo. São Paulo: Martins Fontes, 1988.

RODRIGUEZ, Ernesto et al. Políticas públicas de/para/com juventudes. Brasília: Unesco, 2004.

SUPLICY, Marta. Guia de orientação sexual: diretrizes e metodologia. São Paulo: Casa do Psicólogo, 1994.

Recebido em 07/05/2007

Aprovado em 10/06/2007 